Proceedings

\title{
Anticancer, Antioxidant and Anti-Inflammatory Activities of Chloroform Extracts from Some Centaurea Species ${ }^{\dagger}$
}

\author{
Turgut Sekerler ${ }^{1, *}$, Ali Sen ${ }^{2}$, Leyla Bitis ${ }^{2}$ and Azize Sener ${ }^{1}$ \\ 1 Department of Biochemistry, Faculty of Pharmacy, Marmara University, Istanbul 34668, Turkey; \\ karnitin84@gmail.com (TS); azizesener@hotmail.com \\ 2 Department of Pharmacognosy, Faculty of Pharmacy, Marmara University, Istanbul 34668, Turkey; \\ ali.sen@marmara.edu.tr (A.S.); lbitis@yahoo.com (L.B.) \\ * Correspondence: karnitin84@gmail.com \\ + Presented at the 2nd International Cell Death Research Congress, Izmir, Turkey, 1-4 November 2018. \\ Published: 5 December 2018
}

\begin{abstract}
The aim of this study was to investigate the anticancer activities of five chloroform extracts prepared from the aerial parts of Centeura kilaea Boiss. (CKC), C. cuneifolia Sm. (CCC), C. salicifolia M.Bieb. ex Willd. (CSAC), C. stenolepis Kerner (CSC1 and CSC2) against hepatocellular cancer HepG2 cell line. At the same time, antioxidant and anti-inflammatory activities of the extracts were examined. Anticancer, anti-inflammatory, antioxidant activities of extracts were carried out by MTT, lipoxygenase, DPPH-ABTS methods, respectively. CCC, CSAC and CKC have the highest anticancer activity when compared to other extracts. Similarly, CSAC and CCC had the best antioxidant capacity, while CSAC and CKC showed strong anti-lipoxygenase activity. Among all the tested extracts, the highest amounts of total phenolic were found in the CSAC. The study revealed that CSAC and CCC displays remarkable antioxidant, anticancer and anti-inflammatory activity.
\end{abstract}

Keywords: hepatocellular carcinoma; inflammation; antioxidant

\section{Introduction}

The most common type of liver cancer is known as hepatocellular carcinoma (HCC). HCC is the third cause of deaths due to cancer in the world. Primary liver cancer is the fifth most common cancer in the world and is responsible for the deaths of about half a million people in a year. Five-year survival is reported to be below 5\% [1]. In addition to being the major cause of deaths in Asia and Africa, HCC is increasingly encountered in the west. For this reason the treatment of hepatocellular carcinoma becomes increasingly important. In the studies carried out, expression increases and decreases of genes involved in various processes such as cell growth, cell death, apoptosis, metastasis, signal transduction, metabolism were found. The information obtained shows that the hepatocarcinogenesis process is extremely complex and heterogeneous [2,3]. Therefore, the development of an effective cancer chemotherapeutic agent with fewer side effects has been an urgent need for treatment of hepatocellular carcinoma. For this reason, it is very important to continue research on plants showing anticancer activity in new molecule discovery.

\section{Material and Methods}

Plant samples were collected in the flowering periods from the different regions of Istanbul in 2009 and were identified by Dr. Gizem BULUT and Dr. ŞükranKültür (Table 1).The extraction was done according to the method proposed by Ali et al. with minor modifications [4]. For the first 
extraction process of plants, methanol was used. In addition, the chloroform fraction of methanol extract of $C$. stenolepis obtained by soxhlet method. All extracts were stored under refrigeration for further analysis. Cell lines and cell culture: The human HepG2 liver cancer cell line was obtained from the ATCC and maintained according to the recommendations of the ATCC at $37{ }^{\circ} \mathrm{C}$ and $5 \%$ $\mathrm{CO}_{2}$ in complete DMEM, supplemented with $100 \mathrm{U} / \mathrm{mL}$ penicillin $\mathrm{G}, 100 \mu \mathrm{g} / \mathrm{mL}$ streptomycin and $10 \%$ FBS. Subsequent to reaching confluence, the HepG2 cancer cells were detached using $0.25 \%$ trypsin-EDTA and $1 \times 10^{4}$ cells were seeded into the same complete medium. HepG2 cells were seeded at a density of $1 \times 10^{4} /$ well into 96-well culture plates, and incubated overnight before being exposed to various concentrations of extracts $(200,100,50,25 \mu \mathrm{g} / \mathrm{mL})$. The HepG2 viability and IC 50 were evaluated by Vybrant ${ }^{\circledR}$ MTT Cell Proliferation Assay Kit. Free radical scavenging capacity of extracts were evaluated according to the previously reported procedure using the stable DPPH [4]. ABTS radical-scavenging activity of extracts was determined according to the previously reported procedure [4]. The anti-inflammatory activity was tested according to the method described by Phosrithong et al. [4]. Total phenolic contents of extracts were measured using Folin-Ciocalteau reagent [4]. The data were given as means \pm standard deviations and analysed by one-way analysis of variance (ANOVA) followed by the Tukey's multiple comparison tests using GraphPad Prism 5. Differences between means at $p<0.05, p<0.01, p<0.001$ levels were considered significant.

\section{Results}

Table 1. List of plants used in this work.

\begin{tabular}{llcccc}
\hline \multicolumn{1}{c}{ Botanical Name } & Place of Collection & Endemic & Herbarium No. & Time of Collection \\
\hline 1. & Centaurea stenolepis Kerner & Çatalca/İstanbul & - & $11651^{*}$ & 2009 \\
2. & C. kilaea Boiss. & Çatalca/İstanbul & Endemic & $11712^{*}$ & 2009 \\
3. & C. cuneifolia Sm. & Çatalca/İstanbul & - & $11690^{*}$ & 2009 \\
4. & C. salicifolia M.Bieb. ex Willd. & Şavşat/Atvin & - & $101504^{* *}$ & 2013 \\
\hline
\end{tabular}

* MARE, ${ }^{* *}$ ISTE: The herbarium of the faculty of pharmacy of Marmara and Istanbul, respectively.

HepG2 cells were exposed to CCC, CSAC, CKC, CSC2 and CSC1 extracts at concentrations of $200 \mu \mathrm{g} / \mathrm{mL}, 100 \mu \mathrm{g} / \mathrm{mL}, 50 \mu \mathrm{g} / \mathrm{mL}$ and $25 \mu \mathrm{g} / \mathrm{mL}$ for $24 \mathrm{~h}$. It was observed that each extract had a cytotoxic effect in a dose-dependent manner compared to the control group. The extracts with the highest cytotoxic activity were determined as CCC and CSAC with $0.0024 \mu \mathrm{g} / \mathrm{mL}$ and $3.567 \mu \mathrm{g} / \mathrm{mL}$ IC 50 values, respectively (Table 2). CSC1 and CSAC extracts showed the highest antioxidant activity with IC 50 values of 150.8 and $162.7 \mu \mathrm{g} / \mathrm{mL}$ in DPPH assay. In the ABTS experiment, CSAC and CCC extracts exhibited the best antioxidant activity with $\mathrm{IC}_{50}$ values of 116.4 and $119.5 \mu \mathrm{g} / \mathrm{mL}$.Among all the tested extracts the highest amounts of total phenolic were found in the CSAC $(93.36 \mathrm{mg} / \mathrm{g})$. CSAC and CKC showed strong anti-lipoxygenase activity with IC50 values of 97.04 and 110.0 $\mu \mathrm{g} / \mathrm{mL}$, respectively (Table 2 ).

Table 2. Antioxidant and anti-inflammatory activities and total phenolic contents of chloroform extracts obtained from Centaurea species.

\begin{tabular}{|c|c|c|c|c|c|}
\hline Extracts */Standards & $\begin{array}{l}\text { DPPH Activity } \\
\text { IC }_{50}\left(\mu \mathrm{g} \mathrm{mL}^{-1}\right)\end{array}$ & $\begin{array}{l}\text { ABTS Activity } \\
\text { IC }_{50}\left(\mu \mathrm{g} \mathrm{mL}^{-1}\right)\end{array}$ & $\begin{array}{c}\text { TPC (mg GAE/g } \\
\text { Extract) } * *\end{array}$ & $\begin{array}{l}\text { Cytotoxicity } \\
\mathrm{IC}_{50}\left(\mu \mathrm{g} \mathrm{mL} \mathrm{mL}^{-1}\right)\end{array}$ & 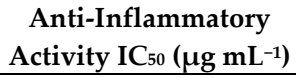 \\
\hline CSC1 & $150.8 \pm 0.35^{c}$ & $129.9 \pm 0.42^{c}$ & $52.36 \pm 1.64$ bc & 1613 & $138.5 \pm 0.21^{\mathrm{f}}$ \\
\hline CSC2 & $258.8 \pm 0.14^{\mathrm{f}}$ & $146.4 \pm 0.99 \mathrm{~d}$ & $49.74 \pm 0.41^{b}$ & 218 & $154.4 \pm 0.99$ е \\
\hline $\mathrm{CCC}$ & $203.3 \pm 1.06^{e}$ & $119.5 \pm 0.07 b$ & $55.40 \pm 0.07 \mathrm{c}$ & 0.002 & $129.4 \pm 6.79 \mathrm{~d}$ \\
\hline CKC & $253.6 \pm 3.47^{f}$ & $147.2 \pm 0.99 \mathrm{~d}$ & $31.57 \pm 1.32 \mathrm{a}$ & 35.930 & $110.0 \pm 3.18^{c}$ \\
\hline CSAC & $162.7 \pm 1.70^{\mathrm{d}}$ & $116.4 \pm 0.35^{b}$ & $93.36 \pm 1.09 \mathrm{~d}$ & 3.567 & $97.04 \pm 0.36^{b}$ \\
\hline Ascorbic acid & $17.60 \pm 0.37 \mathrm{a}$ & $14.50 \pm 0.32 a$ & & & \\
\hline Trolox & $14.54 \pm 0.18^{a}$ & $13.00 \pm 0.211^{a}$ & & & \\
\hline $\begin{array}{c}\text { Butylated } \\
\text { hydroxyanisole }\end{array}$ & $57.15 \pm 0.09 \mathrm{~b}$ & $17.06 \pm 0.58$ a & & & \\
\hline Indometacin & & & & & $22.39 \pm 0.25^{a}$ \\
\hline
\end{tabular}

Results were expressed as gallic acid equivalent (GAE). Each value in the table is represented as mean \pm SD $(n=3)$. Different letter superscripts in the same column indicate significant differences $(p<0.05)$. 


\section{Discussion}

In recent years, a lot of work has been done to discover a new therapeutic molecule on natural products. In this study, we have done research on five different chloroform extracts prepared from the aerial parts of C. kilaea (CKC), C. cuneifolia (CCC), C. salicifolia (CSAC), C. stenolepis (CSC1 and CSC2). There are few studies on the anticancer properties of the extracts obtained from different Centaurea species. Sary et al. reported that Centaurea aegyptiaca extract had cytotoxic effect on HepG2 cells [5]. According to another study, it was reported that Centaurea kilaea Boiss extract had cytotoxic effects on various cancer cell lines [6]. In the present study, C. cuneifolia, C. kilaea, C. salicifolia chloroform extracts showed a dramatically increased cytotoxic effect in less than $24 \mathrm{~h}$ on hepatocarcinoma cell line HepG2. The most effective one was found to be CCC with a IC50 value of $0.002 \mu \mathrm{g} / \mathrm{mL}$. There are many antioxidant studies for different species belonging to the Genus Centaurea. It is emphasized that this feature is caused by the richness of total flavonoid contents.

According to a study, it was stated that the IC 50 values of different Centaurea species against DPPH radical ranged between $1.767-4.665 \mathrm{mg} / \mathrm{mL}$ [7]. According to the results of our study, CSAC and CCC had the best antioxidant capacity. This study showed a good correlation between the cytotoxic effect of the extracts and their antioxidant activity.

In Turkish folk medicine, many Centeurea species have been reported to be used in inflammatory diseases such as rheumatoid arthritis, high fever and headache. According to one study, it was stated that Centeurea methanol extracts showed anti-inflammatory activity in a dose-dependent manner [8]. Similarly, we observed that CKC and CSAC extracts have strong antilipoxygenase activity in the current study.

The results indicated that C. cuneifolia (CCC), C. salicifolia (CSAC), C. kilaea (CKC) was a promising antioxidant, anti-inflammatory and anticancer agents for human hepatocelluler cancer. However, further studies are needed for its therapeutic use with the $\mathrm{IC}_{50}$ value of $0.0024 \mu \mathrm{g} / \mathrm{mL}$, the most efficacious extract (CCC) requires further study in the future for the detection and isolation of anticancer effective molecule.

In addition, the results show that the most efficacious extract (CCC) with the IC 50 value of 0.002 $\mu \mathrm{g} / \mathrm{mL}$, is good candidate for further bioactivity-guided fractionation in the search for new active antitumor compounds.

Acknowledgments: The authors would like to thank Sukran Kultur and Assist.Prof. Gizem Bulut for their help in collection and identification of the plant materials.

\section{References}

1. El-Serag, H.B.; Mason, A. C. Rising incidence of hepatocellular carcinoma in the United States. N. Engl. J. Med. 1999, 340, 745-750.

2. Dennison, J.B.; Jones, D.R.; Renbarger, J.L.; Hall, S.D. Effect of CYP3A5 expression on vincristine metabolism with human liver microsomes. J. Pharmacol. Exp. Ther. 2007, 321, 553-563.

3. Lima, C.F.; Fernandes-Ferreira, M.; Pereira-Wilson, C. Phenolic compounds protect HepG2 cells from oxidative damage: Relevance of glutathione levels. Life Sci. 2006, 79, 2056-2068.

4. Şen, A. Antioxidant and anti-inflammatory activity of fruit, leaf and branch extracts of Paliurus spina-christi P. Mill. Marmara Pharm. J. 2018, 22, 328-333.

5. Orabi, K.Y.; Sary, H.G.; Ayoub, N.A.; Singab, A.N.B. Isolation of a Bioactive Guaianolide from Centaurea aegyptiaca Ethanol Extract. Planta Med. 2013, 79, doi:10.1055/s-0033-1348743.

6. Sen, A.; Turan Ozbas, S.; Akbuga, J.; Bitis, L. In vitro antiproliferative activity of endemic Centaurea kilaea Boiss. Against human tumor cell lines. Müsbed 2015, 5, 149-153.

7. Sen, A.; Bitis, L.; Birteksoz-Tan, S.; Bulut, G. In vitro evaluation of antioxidant and antimicrobial activities of some Centaurea L. species. Marmara Pharm. J. 2013, 17, 42-45.

8. Koca, U.; Peşin Süntar, İ.; Keles, H.; Yesilada, E.; Küpeli Akkol, E. In vivo anti-inflammatory and wound healing activities of Centaurea iberica Trev.ex Spreng. J. Ethnopharmacol. 2009, 126, 551-556. 